\title{
COUNSELING VERSUS ANTIDEPRESSANT THERAPY FOR THE TREATMENT OF MILD TO MODERATE DEPRESSION IN PRIMARY CARE
}

\section{Economic Analysis}

\author{
Paul Miller \\ Clair Chilvers \\ Michael Dewey \\ Katherine Fielding \\ Virginia Gretton \\ Ben Palmer \\ David Weller \\ Trent Institute for Health Services Research, University of Nottingham \\ Richard Churchill \\ Idris Williams \\ Division of General Practice, University of Nottingham
}

\author{
Navjot Bedi \\ Nottingham Healthcare NHS Trust \\ Conor Duggan \\ Division of Forensic Mental Health, Leicester
}

\author{
Alan Lee \\ Dept. of Psychiatry, Queens Medical Centre
}

\section{Glynn Harrison}

Division of Psychiatry, University of Bristol

\footnotetext{
The authors thank Helen Bounds and Joanne Elliott for secretarial and clerical support and Paddy Hawtin for help with data collection. We thank the general practitioners who recruited the patients for this study, and the patients who participated.

Contributors: CC, MD, CD, KF, GH, AL, DW, and IW developed the study protocol. RC, VG, DW, and IW recruited the practices. VG carried out the field work with clinical support from RC. NB, CD, and AL reviewed the case notes and global outcomes. BP, MD, and PM carried out the data analysis. PM carried out economic analyses and wrote the paper, and all authors commented on the drafts.

Funding was provided by NHS Executive Trent. There were no competing interests declared.
} 


\section{Abstract}

Objective: To compare the cost-effectiveness of generic psychological therapy (counseling) with routinely prescribed antidepressant drugs in a naturalistic general practice setting for a follow-up period of 12 months.

Methods: Economic analysis alongside a randomized clinical trial with patient preference arm. Comparison of depression-related health service costs at 12 months. Cost-effectiveness analysis of bootstrapped trial data using net monetary benefits and acceptability curves.

Results: No significant difference between the mean observed costs of patients randomized to antidepressants or to counseling ( $£ 342$ vs $£ 302, p=.56$ [ $t$ test]). If decision makers are not willing to pay more for additional benefits (value placed on extra patient with good outcome, denoted by $K$, is zero), then we find little difference between the treatment modalities in terms of cost-effectiveness. If decision makers do place value on additional benefit $(K>£ 0)$, then the antidepressant group becomes more likely to be cost-effective. This likelihood is in excess of $90 \%$ where decision makers are prepared to pay an additional $£ 2,000$ or more per additional patient with a good global outcome. The mean values for incremental net monetary benefits (INMB) from antidepressants are substantial for higher values of $K($ INMB $=£ 406$ when $K=£ 2,500)$.

Conclusion: For a small proportion of patients, the counseling intervention (as specified in this trial) is a dominant cost-effective strategy. For a larger proportion of patients, the antidepressant intervention (as specified in this trial) is the dominant cost-effective strategy. For the remaining group of patients, cost-effectiveness depends on the value of $K$. Since we cannot observe $K$, acceptability curves are a useful way to inform decision makers.

Keywords: Cost-effectiveness analysis, Depression, Antidepressants, Counseling

Depressive disorders are common, cause significant disability for the individual, and place a substantial burden on health and social services. Most depressive disorders are dealt with in a primary care setting. Psychological therapies are being proposed as a potential alternative to the major treatment modality, antidepressant drugs. Surveys suggest patients may prefer nondrug psychological therapies such as counseling (11). At present little evidence exists to inform decision makers about the relative effectiveness and cost-effectiveness of counseling therapy compared with antidepressant therapy for treatment of depression. In particular, generic counseling is a widely available but poorly evaluated form of psychological therapy in primary care.

Two recent studies have found no significant differences between treatment groups for a range of outcome measures including cost. Harvey et al. (7) carried out a randomized controlled trial (RCT) and economic evaluation comparing counseling in primary care with usual GP care. Bower et al. (3) carried out an RCT and cost-effectiveness analysis comparing nondirective counseling, cognitive-behavior therapy, and usual general practitioner care. As in most cases, these studies were designed to detect clinical differences and economic analysis was "piggybacked" on. Decision makers must not conclude that these treatments are equally cost-effective/cost-ineffective; the absence of evidence is not evidence of absence. Since economic data often have highly skewed distributions, a larger sample size may be required. However, this may generate ethical (clinically overpowered) and financial problems for randomized trials. The Counselling and Antidepressants in Primary Care (CAPC) study was set up to determine the relative effectiveness and cost-effectiveness of generic counseling and antidepressant drugs for the treatment of mild to moderate major depressive episodes in a general practice setting. This paper describes the economic analysis only. The economic evaluation aims to establish the change in resource use and the change in effectiveness brought about by a study intervention (generic counseling) compared with a standard intervention (antidepressant drugs). The economic evaluation ran alongside the prospective RCT and generated patient-specific cost and effect data. To overcome some of the problems of piggyback economic trials, the bootstrapping technique is used to simulate repeated trials. 


\section{METHODS}

Details of the trial methodology and clinical outcomes have been published elsewhere (6). Patients were randomized to either counseling or antidepressants. Patients refusing randomization but agreeing to participate in the patient preference trial were given the treatment of their choice. Treatments and follow-up were identical in the randomized and patient preference groups.

The study was designed to compare treatments as they are provided in day-to-day practice. Thus, clinical responsibility rested with the general practitioner (GP), and the doctor's usual follow-up procedure was encouraged. Patients receiving antidepressants were prescribed the drug most suited to their symptoms. A prescribing protocol was suggested by the study team: dothiepin $(150 \mathrm{mg})$ taken at night; fluoxetine $(20 \mathrm{mg})$ taken once daily; and lofepramine (140-210 mg) taken daily in divided doses. GPs were free to issue a drug not on the schedule if they judged it necessary. Substitution of drugs was permitted during the trial, but the GP was asked to continue treatment at full British National Formulary (BNF) recommended dosage for at least 4 months after remission.

Patients receiving counseling were offered six 50-minute sessions funded by the trial to take place weekly. Six sessions were considered appropriate, since this is comparable to the amount of contact time routinely provided in primary care and workplace counseling services. Extra sessions were requested by some patients and suggested by counselors or GPs, but these were restricted to a maximum of two.

Economic analysis consisted of two stages: a) a detailed costing study quantified resource use in the two treatment arms for a follow-up period of 12 months; and b) cost data and outcomes data collected in the clinical trial were synthesized in a cost-effectiveness analysis.

The costing study involved the identification, measurement, and valuation of resource use. For the 12-month period after enrollment, all depression-related health service resources used were recorded. All GP consultations, drugs prescribed, and use of GP-arranged counseling were recorded from patient notes. Hospital psychiatric outpatient and inpatient visits were abstracted from case notes. The costs used in Tables 1 and 2 are for the 12-month study period and are categorized as: a) all antidepressants prescribed; b) all counseling received; c) all direct depression treatment combined (antidepressants and counseling together, $\mathrm{a}+\mathrm{b}$ ); d) all GP consultations relating to depression (as indicated by notes); e) all GP consultations (including d); f) psychiatric inpatient hospital stays; and g) psychiatric outpatient hospital visits. The relevant aggregated total is given as: all depression-related health services $(c+d+f+g)$.

Unit cost data were obtained from Netten et al. (9), BNF (5), and invoices from counselors in the trial. Analysis of cost data follows Barber and Thompson (1) and includes measures of location (mean and median), variability (interquartile range), shape of distribution (skew: coefficient of asymmetry of distribution), and precision (95\% confidence intervals). Inferences about the average cost differences are based on comparison of arithmetic means given by the $t$ test. Results are also presented for the nonparametric Mann Whitney $U$ test, addressing differences in medians and shape of the cost distribution between the groups. Costs were not trimmed for outliers or transformed, so analysis is based on mean costs.

Barber and Thompson (2) also advocate the use of the bootstrapping technique to confirm the validity of results based on a comparison of mean costs using the standard $t$ test. This is especially important where sample size is low and severe skew is present. There is ongoing methodologic debate over the robustness of the bootstrap and methods based on normality theory compared with a Bayesian approach (10). In this study we chose to follow the Barber and Thompson approach. 
Table 1. Twelve-month Resource Use (Randomized Patients)

\begin{tabular}{|c|c|c|c|c|c|}
\hline Cost & & $\begin{array}{l}\text { Antidepressant } \\
\text { group } \\
(\mathrm{n}=51)\end{array}$ & $\begin{array}{c}\text { Counseling } \\
\text { group } \\
(\mathrm{n}=52)\end{array}$ & $t$ test & $\begin{array}{l}\text { Mann- } \\
\text { Whitney } \\
\text { U test }\end{array}$ \\
\hline \multirow{6}{*}{$\begin{array}{l}\text { All } \\
\quad \text { antidepressants }\end{array}$} & Mean (SE) & $£ 84.16$ (12.45) & $£ 21.69(5.97)$ & $p<.001$ & $p<.001$ \\
\hline & $95 \%$ CI & L: $£ 59.14$ & L: $£ 9.71$ & & \\
\hline & & U: $£ 109.19$ & $\mathrm{U}: £ 33.68$ & & \\
\hline & Median & $£ 46.38$ & $£ 0$ & & \\
\hline & IQR & $£ 128.78$ & $£ 30.86$ & & \\
\hline & Skewness & 1.33 & 2.22 & & \\
\hline \multirow{6}{*}{$\begin{array}{l}\text { All } \\
\text { counseling }\end{array}$} & Mean (SE) & $£ 7.06(2.79)$ & $£ 94.23(7.0)$ & $p<.001$ & $p<.001$ \\
\hline & $95 \%$ CI & L: $£ 1.49$ & L: $£ 80.18$ & & \\
\hline & & $\mathrm{U}: £ 12.91$ & $\mathrm{U}: £ 108.28$ & & \\
\hline & Median & $£ 0$ & $£ 120$ & & \\
\hline & IQR & $£ 0$ & $£ 80.00$ & & \\
\hline & Skewness & 2.88 & -0.48 & & \\
\hline \multirow{6}{*}{$\begin{array}{l}\text { All direct } \\
\text { depression } \\
\text { treatment }\end{array}$} & Mean (SE) & $£ 89.57(12.04)$ & $£ 115.92(10.0)$ & $p=.095$ & $p=.031$ \\
\hline & $95 \% \mathrm{CI}$ & L: $£ 65.39$ & L: $£ 95.83$ & & \\
\hline & & $\mathrm{U}: £ 113.75$ & $\mathrm{U}: £ 136.01$ & & \\
\hline & Median & $£ 73.39$ & $£ 120$ & & \\
\hline & IQR & $£ 126$ & $£ 78.92$ & & \\
\hline & Skewness & 1.25 & 0.48 & & \\
\hline \multirow{6}{*}{$\begin{array}{l}\text { Depression- } \\
\text { related GP } \\
\text { visits }\end{array}$} & Mean (SE) & $£ 70.20(6.93)$ & $£ 56.54(9.76)$ & $p=.255$ & $p=.025$ \\
\hline & $95 \%$ CI & L: $£ 55.98$ & L: $£ 36.94$ & & \\
\hline & & $\mathrm{U}: £ 84.42$ & $\mathrm{U}: £ 76.14$ & & \\
\hline & Median & $£ 60$ & $£ 30$ & & \\
\hline & IQR & $£ 75$ & $£ 90$ & & \\
\hline & Skewness & 1.08 & 2.43 & & \\
\hline \multirow[t]{6}{*}{ All GP visits } & Mean (SE) & $£ 132.65(10.51)$ & $£ 126.63$ (12.44) & $p=.713$ & $p=.446$ \\
\hline & $95 \% \mathrm{CI}$ & L: $£ 111.53$ & L: $£ 101.65$ & & \\
\hline & & $\mathrm{U}: £ 153.76$ & $\mathrm{U}: £ 151.61$ & & \\
\hline & Median & $£ 135$ & $£ 105$ & & \\
\hline & IQR & $£ 90$ & $£ 86.25$ & & \\
\hline & Skewness & 1.50 & 1.26 & & \\
\hline \multirow{6}{*}{$\begin{array}{l}\text { Psychiatric } \\
\text { inpatient }\end{array}$} & Mean (SE) & $£ 95.13(48.08)$ & $£ 36.18(22.90)$ & $p=.268$ & $p=.513$ \\
\hline & $95 \% \mathrm{CI}$ & $\mathrm{L}:-£ 1.45$ & L: $-£ 9.81$ & & \\
\hline & & $\mathrm{U}: £ 191.70$ & $\mathrm{U}: £ 82.16$ & & \\
\hline & Median & $£ 0$ & $£ 0$ & & \\
\hline & IQR & $£ 0$ & $£ 0$ & & \\
\hline & Skewness & 4.78 & 6.03 & & \\
\hline \multirow{6}{*}{$\begin{array}{l}\text { Psychiatric } \\
\text { outpatient }\end{array}$} & Mean (SE) & $£ 86.10$ (19.07) & $£ 89.72(19.05)$ & $p=.893$ & $p=.664$ \\
\hline & $95 \% \mathrm{CI}$ & L: $£ 47.79$ & L: $£ 51.48$ & & \\
\hline & & U: $£ 124.40$ & $\mathrm{U}: £ 127.96$ & & \\
\hline & Median & $£ 0$ & $£ 0$ & & \\
\hline & IQR & $£ 182.96$ & $£ 182.96$ & & \\
\hline & Skewness & 1.69 & 2.49 & & \\
\hline \multirow{6}{*}{$\begin{array}{l}\text { All depression- } \\
\text { related health } \\
\text { services }^{\mathrm{a}}\end{array}$} & Mean (SE) & $£ 343.64(61.87)^{\mathrm{b}}$ & $£ 301.63(37.72)^{\mathrm{c}}$ & $p=.561$ & $p=.777$ \\
\hline & $95 \%$ CI & L: $£ 219.45$ & L: $£ 225.91$ & & \\
\hline & & $\mathrm{U}: £ 467.82$ & $\mathrm{U}: £ 377.35$ & & \\
\hline & Median & $£ 265.30$ & $£ 235.74$ & & \\
\hline & IQR & $£ 262.01$ & $£ 244.10$ & & \\
\hline & Skewness & 3.54 & 2.24 & & \\
\hline
\end{tabular}

$\overline{{ }^{a} \text { Antidepressants + counseling + GP depression-related visits + psychiatric inpatient admissions + psychiatric }}$ outpatient visits.

${ }^{\mathrm{b}}$ Mean of 25 prescriptions for antidepressants, 5 depression-related GP visits. In total 7 people in this group received counseling; there were 9 inpatient admissions and 20 outpatient visits.

${ }^{\mathrm{c}}$ Mean of 2 prescriptions for antidepressants, 4 depression-related GP visits. In total 47 people in this group received counseling; there were 7 inpatient admissions and 24 outpatient visits. 
Miller et al.

Table 2. Twelve-month Resource Use (Patient Preference)

\begin{tabular}{|c|c|c|c|c|c|}
\hline Cost & & $\begin{array}{l}\text { Antidepressant } \\
\text { group } \\
(\mathrm{n}=76)\end{array}$ & $\begin{array}{c}\text { Counseling } \\
\text { group } \\
(\mathrm{n}=139)\end{array}$ & $t$ test & $\begin{array}{l}\text { Mann- } \\
\text { Whitney } \\
\text { U test }\end{array}$ \\
\hline \multirow{6}{*}{$\begin{array}{l}\text { All } \\
\text { antidepressants }\end{array}$} & Mean (SE) & $£ 76.08(10.38)$ & $£ 35.76(6.23)$ & $p<.001$ & $p<.001$ \\
\hline & $95 \%$ CI & L: $£ 55.41$ & L: $£ 23.42$ & & \\
\hline & & $\mathrm{U}: £ 96.75$ & $\mathrm{U}: £ 48.10$ & & \\
\hline & Median & $£ 32.73$ & 0 & & \\
\hline & IQR & $£ 104.99$ & $£ 48.45$ & & \\
\hline & Skewness & 1.50 & 2.78 & & \\
\hline \multirow{6}{*}{$\begin{array}{l}\text { All } \\
\text { counseling }\end{array}$} & Mean (SE) & $£ 3$ & $£ 106.03$ (4.54) & $p<.001$ & $p<.001$ \\
\hline & $95 \% \mathrm{CI}$ & L: $-£ 2.49$ & L: $£ 97.06$ & & \\
\hline & & U: $£ 8.49$ & U: £115 & & \\
\hline & Median & 0 & $£ 120$ & & \\
\hline & IQR & 0 & $£ 40$ & & \\
\hline & Skewness & 8.84 & -0.26 & & \\
\hline \multirow{6}{*}{$\begin{array}{l}\text { All direct } \\
\text { depression } \\
\text { treatment }\end{array}$} & Mean (SE) & $£ 75.28(10.91)$ & $£ 141.53$ (7.69) & $p<.001$ & $p<.001$ \\
\hline & $95 \% \mathrm{CI}$ & L: $£ 53.55$ & L: $£ 126.32$ & & \\
\hline & & U: $£ 97.01$ & U: $£ 156.75$ & & \\
\hline & Median & $£ 30.15$ & $£ 120$ & & \\
\hline & IQR & $£ 88.74$ & $£ 76.70$ & & \\
\hline & Skewness & 1.83 & 1.47 & & \\
\hline \multirow{6}{*}{$\begin{array}{l}\text { Depression- } \\
\text { related GP } \\
\text { visits }\end{array}$} & Mean (SE) & $£ 66.12$ (6.25) & $£ 47.24(5.27)$ & $p=.027$ & $p=.001$ \\
\hline & $95 \%$ CI & L: $£ 53.68$ & L: $£ 36.82$ & & \\
\hline & & U: $£ 78.56$ & U: $£ 57.66$ & & \\
\hline & Median & $£ 60$ & $£ 15$ & & \\
\hline & IQR & $£ 71.25$ & $£ 75$ & & \\
\hline & Skewness & 1.17 & 1.91 & & \\
\hline \multirow[t]{6}{*}{ All GP visits } & Mean (SE) & $£ 129.47(8.57)$ & $£ 115.79(8.97)$ & $p=.319$ & $p=.039$ \\
\hline & $95 \% \mathrm{CI}$ & L: $£ 112.41$ & L: $£ 98.05$ & & \\
\hline & & $\mathrm{U}: £ 146.54$ & U: $£ 133.53$ & & \\
\hline & Median & $£ 120$ & $£ 105$ & & \\
\hline & IQR & $£ 105$ & $£ 120$ & & \\
\hline & Skewness & 0.86 & 2.42 & & \\
\hline \multirow{6}{*}{$\begin{array}{l}\text { Psychiatric } \\
\text { inpatient }\end{array}$} & Mean (SE) & $£ 39.15(13.31)$ & $£ 39.62(12.82)$ & $p=.982$ & $p=.735$ \\
\hline & $95 \%$ CI & L: $£ 12.65$ & L: $£ 14.26$ & & \\
\hline & & U: $£ 65.66$ & U: £64.97 & & \\
\hline & Median & 0 & 0 & & \\
\hline & IQR & 0 & 0 & & \\
\hline & Skewness & 3.86 & 5.32 & & \\
\hline \multirow{6}{*}{$\begin{array}{l}\text { Psychiatric } \\
\text { outpatient }\end{array}$} & Mean (SE) & $£ 89.07$ (19.16) & $£ 107.39$ (14.75) & $p=.454$ & $p=.427$ \\
\hline & $95 \% \mathrm{CI}$ & L: $£ 50.91$ & L: $£ 78.21$ & & \\
\hline & & $\mathrm{U}: £ 127.23$ & U: $£ 136.57$ & & \\
\hline & Median & 0 & 0 & & \\
\hline & IQR & $£ 91.48$ & $£ 182.96$ & & \\
\hline & Skewness & 2.88 & 1.97 & & \\
\hline \multirow{6}{*}{$\begin{array}{l}\text { All depression- } \\
\text { related health } \\
\text { services }^{\mathrm{a}}\end{array}$} & Mean (SE) & $£ 263.41(33.84)^{\mathrm{b}}$ & $£ 335.63(24.86)^{\mathfrak{c}}$ & $p=.084$ & $p=.005$ \\
\hline & $95 \% \mathrm{CI}$ & L: $£ 196.04$ & L: $£ 286.48$ & & \\
\hline & & $\mathrm{U}: £ 330.77$ & $\mathrm{U}: £ 384.77$ & & \\
\hline & Median & $£ 184.33$ & $£ 224.52$ & & \\
\hline & IQR & $£ 249.69$ & $£ 272.78$ & & \\
\hline & Skewness & 2.3 & 1.69 & & \\
\hline
\end{tabular}

\footnotetext{
${ }^{\mathrm{a}}$ Antidepressants + counseling + GP depression-related visits + psychiatric inpatient admissions + psychiatric outpatient visits.

${ }^{\mathrm{b}}$ Mean of 55 prescriptions for antidepressants, 8 depression-related GP visits. In total 2 people in this group received counseling; there were 15 inpatient admissions and 29 outpatient visits.

${ }^{\mathrm{c}}$ Mean of 9 prescriptions for antidepressants, 9 depression-related GP visits. In total 126 people in this group received counseling; there were 25 inpatient admissions and 59 outpatient visits.
} 
In the clinical trial, the main outcome measures at 12 months were (6):

- Beck Depression Inventory score completed by the patient;

- Time to remission;

- Global outcome, classified as good, moderate, poor, or unknown; and

- The Research Diagnostic Criteria (RDC) completed by the general practitioner.

Remission was defined as an RDC score of less than 4, a Beck score of less than 10, or clear documentation in the GP notes that the patient was well. "Relapsed" was defined as deterioration within 6 months of remission, and "recurrence" as deterioration after 6 months of remission.

Global outcome was assessed by a psychiatrist (NB) blind to treatment allocation, using the RDC, Beck score, and GP notes. The advantage of this global outcome measure was that in the absence of RDC or Beck scores, an estimate could be made based on information obtained from the notes. The outcome was good if the patient responded to treatment within 8 weeks and then remained well, moderate if either the patient was slow to respond but then remained well or was well initially and then became unwell, and poor if the patient remained depressed throughout. The criteria for being well were the same as the criteria for remission.

The cost-effectiveness analysis used the psychiatrist's assessment of global outcome as the measure of effectiveness since it represents the most comprehensive measure. This is presented as a simple binary outcome: probability of good global outcome versus not a good global outcome.

To account for possible sampling error and to recognize uncertainty around cost and effect data, a distribution of these estimates was generated using the bootstrapping technique (4). Bootstrapping is a technique that can simulate a distribution of data by repeatedly resampling (with replacement) from the observed sample. Since there is covariation between cost and effect variables, we used 2,000 iterations of resampled estimates for pairs of costs and effect in all bootstrap simulations. These bootstrapped estimates can then be plotted on the cost-effectiveness plane (Figure 1).

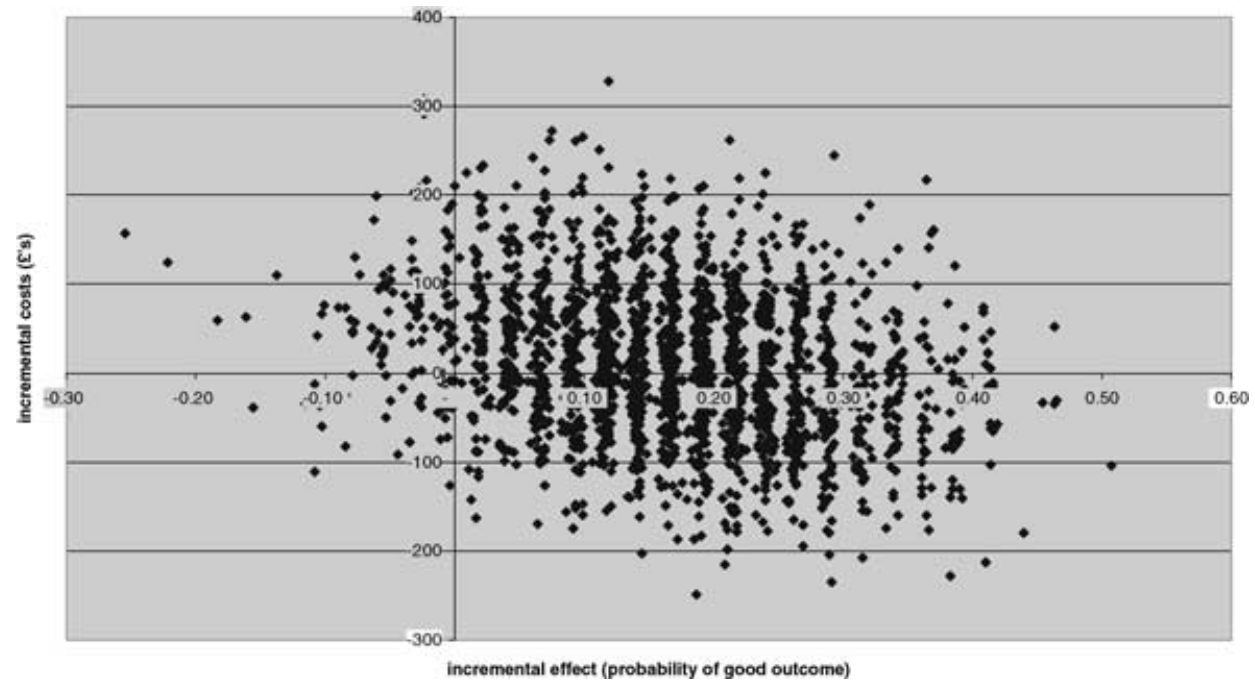

Figure 1. Antidepressants versus counseling (origin) (randomized patients). 
The origin on the cost-effectiveness plane represents the comparator strategy (counseling), while each data point represents the observed change in cost and effect using the intervention strategy (antidepressants). This highlights the distribution of cost and effect data. Points in the southeast quadrant (lower costs, higher benefits) dominate the comparator, while points in the northwest quadrant (higher costs, lower benefits) are dominated by the comparator. Points in the remaining two quadrants (northeast and southwest) may or may not be desirable, depending on decision makers ${ }^{1}$ values and objectives. Incremental cost effectiveness ratios (ICER $=[$ cost of antidepressant therapy - cost of counseling)/(effect of antidepressant therapy - effect of counseling]) are only calculated for points in these two quadrants. Decision makers must determine their maximum acceptable ICER (denoted by $K$ ); i.e., how much they would pay for additional units of benefit. Using a range of values for $K$, it is possible to simplify from ratios and present results on the incremental net monetary benefit (INMB) scale. We know that a decision should be made to implement an intervention when:

$$
I C E R=\frac{\Delta \text { Cost }}{\Delta E f f e c t}<K
$$

(since this is when it will be labeled as cost-effective). By rearranging this equation, the decision rule on the INMB scale is to implement when:

$$
I N M B=K . \Delta E f f e c t-\Delta C o s t>0 .
$$

That is, where the monetized value of the change in effect less the change in cost brought about by the intervention is positive $(K$ can take values $0-\infty)$. Since it is not a ratio statistic, the INMB scale is much easier to analyze.

\section{RESULTS}

A total of 103 patients with major depression were randomly allocated to either generic counseling or antidepressant drugs in primary care. Another 220 patients refused randomization but chose their treatment; $64 \%$ of them chose counseling. Complete data at 12 months on global outcome was available for 81 randomized patients and 163 patient preference patients. For the remaining patients, global outcome was classified as unknown due to insufficient data available to reach a conclusion, caused mostly by patient nonattendance at 12 month GP follow-up. Nine patients randomized to antidepressants had unknown outcomes, and their mean costs were significantly lower than those with outcome data (£177 vs $£ 379, p=.035$ ). Thirteen patients randomized to counseling had unknown outcomes, and their mean costs were significantly lower than those with outcome data ( $£ 103$ vs $£ 368$, $p<.001$ ). Twenty-one patients choosing antidepressants had unknown outcomes, and their mean costs were not different to those with outcome data ( $£ 197$ vs $£ 287, p=.189$ ). Thirtyseven patients choosing counseling had unknown outcomes, and their mean costs were not different to those with outcome data. ( $£ 339$ vs $£ 334, p=.943$ ). Cost data were complete for randomized patients, but five patients in the preference arm had missing cost data. In the primary analysis, patients with missing data are excluded; sensitivity analysis includes assumed values for randomized patients without outcome data.

\section{Cost Analysis}

Randomized Group. There was no significant difference between the two randomized treatment groups in the cost of all depression-related health care observed in this study for a period of 12 months after entry to the trial (Table 1). The treatment group to which patients 
were initially randomized (for a period of 8 weeks) led to significantly higher costs for that form of treatment after 12 months. Thus, patients randomized to counseling have higher counseling costs at 12 months than those randomized to antidepressants and vice versa.

Since many patients received both treatment modalities within the 12-month period, it is useful to consider the overall cost of direct depression treatment (counseling + antidepressants). We observed a significant cost difference between the treatment groups using the nonparametric test, with higher combined costs for those initially randomized to counseling. On the other hand, we also observed significantly higher (nonparametric test) GP depression-related consultation costs in the antidepressant group.

There was no significant difference between the treatment groups in terms of psychiatric inpatient or outpatient costs or in terms of total GP consultations. The low sample size and levels of skew in these data may contribute to the nonsignificant difference in the aggregated totals.

Patient Preference Group. For patients choosing their treatment modality, a significant difference between the groups in terms of the overall cost of all depression-related health services was observed (Table 2) (using the nonparametric test). Patients choosing counseling incurred higher median costs than patients choosing antidepressants ( $£ 225 \mathrm{vs}$ $£ 184$ ); those mean costs were also higher but not significantly. Direct depression treatment costs were considerably higher in the counseling group and were not offset by significantly higher GP consultation costs in the antidepressant group. There is no significant difference between the treatment groups in terms of psychiatric inpatient or outpatient costs, but again these data are skewed.

Randomized Versus Patient Preference. For the group of patients receiving antidepressants, no significant overall cost differences between the randomized and patient preference groups were observed. The only statistically significant difference was in terms of observed counseling costs. Patients who chose antidepressants initially had lower counseling costs than those randomized to antidepressants. For the group of patients receiving counseling, no significant overall cost differences between the randomized and patient preference groups were observed.

\section{Cost-effectiveness Analysis}

Point estimates of cost-effectiveness ratios based on the incremental differences in mean observed cost and effect do not capture uncertainty in the sample data on which they are based. Confidence intervals for cost data and for effect data are presented, but often not for cost-effectiveness ratios. Statistical inference from a ratio is difficult, and the policy implications from point estimates uncertain. The bootstrapping technique generates a distribution of cost-effectiveness data, which can enable statistical inference and be more informative to policy decision makers. The 2,000 bootstrapped means for cost and effect pairs are plotted on the cost-effectiveness plane. Figure 1 shows the range of cost-effectiveness results for antidepressants when compared with counseling (represented by the origin). The proportion of the distribution in each quadrant informs decision makers of the likelihood of cost and effect differences between the treatment modalities. For example, a point in the northeast quadrant shows the case where antidepressants were more costly and more effective than counseling. Figure 1 shows the distribution around the origin with points in all four quadrants.

To summarize the whole distribution of cost-effectiveness results, a so-called costeffectiveness acceptability curve (CEAC) can be constructed (8). This gives an estimate of the proportion of the simulated distribution of cost and effect pairs that lie below a given threshold (the maximum value a decision maker is prepared to pay for a unit of effect $-K$ ) or, more simply, the proportion that generate positive net (monetary) benefits. Figure 2 shows the range of probability that antidepressant therapy will be cost-effective when compared 


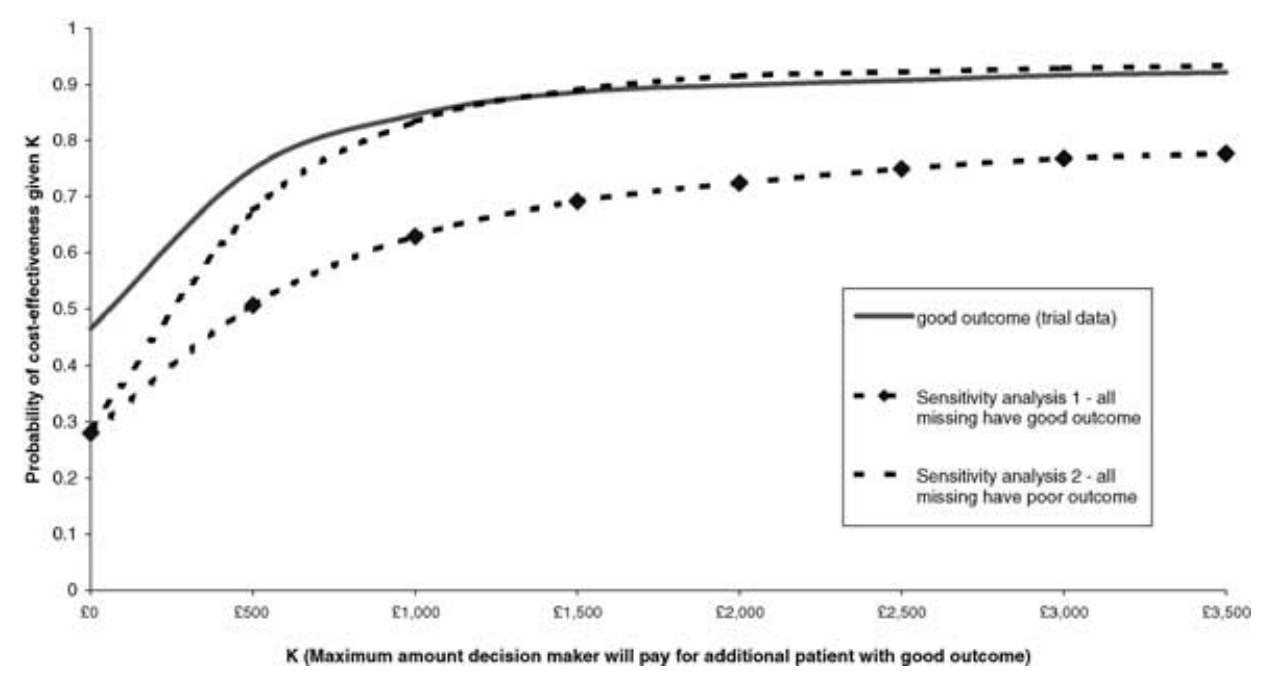

Figure 2. Cost-effectiveness acceptability curves: antidepressants compared with counseling (randomized patients).

with counseling for randomized patients. When decision makers are not prepared to pay any additional cost to obtain one extra patient with a good outcome $(K=0)$, there is around a 0.45 chance that antidepressants will be cost-effective (compared with counseling). This is the point where the curve intercepts the $y$-axis and represents the cost difference between the treatments. It is also shown in Figure 1, since approximately half the data lays either side of the horizontal axis (45\% lower costs and 55\% higher costs than counseling). Based on existing evidence, there is too much uncertainty at this point to claim that antidepressants are likely to be cost-effective.

However, if decision makers are prepared to pay more for more benefit-additional effectiveness is valued highly (in monetary terms) - then the probability of cost-effectiveness increases rapidly. The level of certainty about cost-effectiveness increases asymptotically for higher values of $K$. Thus, the probability that antidepressants are more cost-effective is 0.75 when $K=£ 500$ and above 0.90 when $K>£ 2,000$. The acceptability curve does not provide information on the magnitude of net benefits, only the proportion of times it is positive. Mean INMB is negative when $\mathrm{k}=0$ since the acceptability curve intercepts the axis below the 0.5 point. Average INMB is substantial as $K$ increases. These data are also more normally distributed.

\section{Sensitivity Analysis}

Two sensitivity analyses were conducted to show the possible impact of unknown outcome data for randomized patients. Outcome data were missing for 22 randomized patients (13 counseling, 9 antidepressants); we found their depression-related healthcare resource use to be significantly lower than patients with 12-month outcome data. The first sensitivity analysis assumed that all these patients achieved good global outcome. The second analysis assumed that all these achieved poor global outcome. The bootstrapping simulation was then used to generate the new distribution for the net benefit statistic. The impact on the acceptability curve is shown in Figure 2. Assuming good outcomes for missing data lowers the probability that antidepressants are cost-effective for all values of $K$. Assuming poor outcomes for missing data lowers slightly the probability that antidepressants are costeffective for values of $K<£ 1,500$ but increases the probability for values of $K>£ 1,500$. In both analyses the mean value for net benefit remains positive when $K \geq £ 500$. 


\section{DISCUSSION}

Using conventional analysis, this study found no significant difference between randomized treatment groups in either outcomes or costs at 12 months. This is in accordance with other studies $(3 ; 7)$. As with most studies, the CAPC study was powered to detect clinical differences (Beck scores) between the two treatment groups. Thus, the finding of no statistically significant differences between the randomized groups in terms of global outcome and cost to the NHS does not imply that the treatment modalities are equally cost-effective.

Using net-benefits and cost-effectiveness acceptability curves after recalculating mean costs and effects for both groups by resampling 2,000 times from the observed data provides decision makers with more information. First, if decision makers are not willing to pay more for additional benefits (more patients with good global outcome: free from depression), then given the current evidence we find little difference between the treatment modalities in terms of cost-effectiveness. Sensitivity analyses show the counseling group is more likely to be less costly than the antidepressant group. Second, if decision makers do place value on additional benefit $(K>0)$, then the antidepressants group becomes more likely to be cost-effective when compared with the counseling group. This likelihood is in excess of $90 \%$ where decision makers are prepared to pay an additional $£ 2,000$ or more per additional patient with a good global outcome. In the most negative sensitivity analysis, the probability that antidepressants are cost-effective exceeds 0.5 when $K=£ 500$ and Rises above 0.75 for higher values of $K$. As certain antidepressant drugs such as fluoxetine ${ }^{2}$ come to the end of their patent protection period, it is possible that their cost may be reduced. This will only enhance the probability of antidepressants being more cost-effective than counseling.

\section{POLICY IMPLICATIONS}

This analysis has shown that for a small proportion of patients with mild to moderate depression, the counseling intervention (as specified in this trial) is a dominant cost-effective strategy. For a larger proportion of patients, the antidepressant intervention (as specified in this trial) is the dominant cost-effective strategy. For the remaining group of patients, costeffectiveness depends on the value of $K$ : the amount decision makers value an additional patient with positive outcome. Since we cannot observe $K$, acceptability curves are a useful way to inform decision makers of current evidence in light of their own values. Further research is needed to understand the determinants of cost-effectiveness for specific groups of patients. Counseling and/or antidepressants could then be targeted to maximize the overall efficiency of resources used to manage depression.

\section{NOTES}

${ }^{1}$ It is conventional to analyze changes brought about by "new" treatment compared with "current" treatment, so that current treatment is at the origin on the CE plane. We have presented antidepressants compared with counseling just because of the nature of our data; analysis of counseling compared with antidepressants (as the origin) would be equally valid.

2 Prozac.

\section{REFERENCES}

1. Barber J, Thompson S. Analysis and interpretation of cost data in randomised controlled trials: Review of published studies. BMJ. 1998;317:1195-1200.

2. Barber J, Thompson S. Analysis of cost data in randomised trials: An application of the nonparametric bootstrap. Stat Med. 2000;19:2319-3236.

3. Bower P, Byford S, Sibbald B, et al. Randomised controlled trial of non-directive counselling, cognitive-behaviour therapy, and usual general practitioner care for patients with depression, II: Cost effectiveness. BMJ. 2000;321:1389-1392. 
Miller et al.

4. Briggs A, Gray A. Handling uncertainty when performing economic evaluation of healthcare interventions. Health Technol Assess. 1999;3.

5. British Medical Association and Royal Pharmaceutical Society of Great Britain. British National Formulary. 1996; March (31).

6. Chilvers C, Dewey M, Fielding K, et al. Antidepressant drugs and generic counselling for treatment of major depression in primary care: Randomised trial with patient preference arms. $B M J$. 2001;322:772-775.

7. Harvey I, Nelson SJ, Lyons RA, et al. A randomized controlled trial and economic evaluation of counselling in primary care. Br J Gen Pract. 1998;48:1043-1048.

8. Lothgren M, Zethraeus N. Definition, interpretation and calculation of cost-effectiveness acceptability curves. Health Econ. 2000;9:623-630.

9. Netten A, et al. Unit costs of community care. PSSRU, University of Kent; 1995.

10. O'Hagan A, Stevens J. Assessing and comparing costs: How robust are the bootstrap and methods based on asymptotic normality? Health Econ. In press. Available at: www.interscience.wiley.com.

11. Priest R, Vize C, Roberts M, Tylee A. Lay people's attitudes to treatment of depression: Results of opinion poll for Defeat Depression Campaign just before its launch. BMJ. 1996;313:858-859. 